i Universidade Nova de Lisboa, Instituto de História Contemporânea, Portugal raquel_cardeira_varela@yahoo.co.uk

ii Universidade Nova de Lisboa, Instituto de História Contemporânea, Portugal antonio_paco2003@yahoo.co.uk

iii Universidade Nova de Lisboa,

Faculdade de Ciências Sociais e Humanas, Portugal

Raquel Varelai joana.sj.alcantara@gmail.com

iv Universidade de Lisboa,

Instituto de Ciências Sociais, Portugal

pma.ferreira@ics.ul.pt

\title{
AUTOGESTÃO E CRISE ECONÔMICA NA REVOLUÇÃO PORTUGUESA (1974-1975)
}

No tempo do patrão nem apetecia trabalhar porque estava sempre a berrar connosco e uma pessoa nem apetecia trabalhar, apetecia até oferecer-lhe porrada e mais outras coisas (Rádio e Televisão de Portugal, 30 de julho de I975). ${ }^{\text {I }}$

\section{A ÚlTIMA REVOLUÇÃo EUROPEIA DO SÉcULO XX}

No dia 25 de abril de 1974 um golpe levado a cabo pelo Movimento das Forças Armadas (MFA) põe fim à ditadura portuguesa por discordar das guerras que Portugal travava com suas colônias africanas e que duravam treze anos. A ditadura, por sua vez, já se arrastava por 48 anos, primeiramente sob a direção de António Salazar e, depois de I968, sob a chefia de Marcelo Caetano.

De imediato, e contra o apelo dos militares que dirigiram o golpe - que insistiam pelo rádio para que a população ficasse em casa -, milhares de pessoas saíram às ruas, sobretudo em Lisboa e Porto. Foi com elas à porta, a gritar "morte ao fascismo", que no Quartel do Carmo, em Lisboa, o Governo foi cercado; as portas das prisões de Caxias e Peniche abriram-se para que saíssem todos os presos políticos; a PIDE/DGC, a polícia política, foi desmantelada; a sede do jornal do regime A Época foi atacada e a censura abolida.

No dia 28 de abril, três dias depois do golpe, os moradores do bairro social (pobre) da Boavista, em Lisboa, ocupam casas vagas e recusam-se a sair, apesar de intimados pelos militares e pela polícia. A partir do dia 29 de abril 
os bancários começam a controlar a saída de capitais dos bancos e montam piquetes às portas destes; no mesmo dia, os empregados de escritório ocupam o sindicato (os sindicatos estavam limitados na sua liberdade durante a ditadura e as suas direções eram pró-regime) e expulsam a direção; no dia seguinte, vários sindicatos ocupam o Ministério das Corporações e Segurança Social, que passa a se chamar Ministério do Trabalho; nesse dia, ıo mil estudantes reúnem-se em plenário no Instituto Superior Técnico, a escola superior mais importante do país, de Engenharia, e os trabalhadores da construção civil demitem a direção do sindicato e ocupam sua sede. Começa a greve na Transul, empresa de transportes, e é formado o Movimento de Libertação da Mulher (MLM).

A manifestação do $I^{\circ}$ de Maio - que passa ser o Dia do Trabalhador reúne cerca de meio milhão de pessoas em Lisboa. Medeiros Ferreira cita estudos que apontam para uma centena de manifestações em que participaram cerca de um milhão de portugueses para ouvirem 200 oradores (Ferreira, I994: 35) em todo o país. As ocupações de casas sucedem-se; nos primeiros quinze dias de maio há greves, paralisações e, em alguns casos, ocupações em dezenas de fábricas e empresas. Várias manifestações, dirigidas sobretudo pela extrema-esquerda, condenam a guerra colonial (nos dias 3, 4 e 5 de maio, entre outras).

Tinha começado a revolução portuguesa, num país da Europa Ocidental, no meio da década de I970, no espaço geoestratégico da Organização do Tratado do Atlântico Norte (OTAN).

O império português ruiu tarde, em I974, depois de ter mobilizado quase dois milhões de trabalhadores forçados (nas minas de África do Sul, plantações de algodão de Angola, entre outras culturas) e uma guerra de treze anos - I96I-I974 - para impedir a independência de Angola, Cabo-Verde, Moçambique e Guiné Bissau. Mas a sua estrutura anquilosada levou à ruptura social mais importante da Europa do pós-guerra - foi tão grande a queda quão longeva fora a sua duração, de tal forma que nenhum historiador até hoje conseguiu esclarecer quantas reuniões de trabalhadores houve em todo o país só na primeira semana que se seguiu ao golpe do MFA porque foram centenas, talvez milhares. ${ }^{2}$

Anacrônico, brutal nas colônias, com congelamento da mobilidade social da metrópole que tinha pouco a oferecer a seus jovens - um milhão e meio de pessoas emigraram do País, sobretudo para a Europa central, entre ig6o e I 974 (Barreto, 2005) -, o império levou o Estado português até próximo do colapso, militar e financeiro, até que um movimento de capitães deu um golpe militar para pôr fim à guerra, no dia 25 de abril de I974. O golpe militar deu-se, assim, com escassa resistência, contabilizando-se no total quatro mortos, alvos dos disparos da polícia política cercada.

A revolução portuguesa, argumentamos noutro trabalho, tem quatro características determinantes que podem ajudar a explicar o seu alcance que, apesar de ter se dado num pequeno país, deu-se já na década de I970, com 
uma dimensão de controle operário e estancamento do processo de acumulação inusitados nesta região naquele período:

I. É um processo que nasce de uma derrota militar de um exército regular por movimentos revolucionários guerrilheiros apoiados nos camponeses da Guiné-Bissau, Angola e Moçambique;

2. Essa derrota combinou-se com a mais grave crise econômica do capitalismo do pós-guerra, iniciada em I973;

3. É marcada pelo protagonismo do movimento operário;

4. É marcada pelas especificidades desse mesmo movimento operário português, caracterizado pela grande massa de jovens camponeses recém-qualificados que vão do campo para a cidade na década de ig6o, e pela desorganização política e sindical e a sua concentração na cintura industrial de Lisboa. A não existência de organizações livres e democráticas de trabalhadores, um calcanhar de Aquiles do movimento operário português durante o Estado Novo, foi concomitantemente parte da radicalização da revolução porque a ausência destas organizações na maioria das fábricas e empresas do país determinou a abertura espontânea do espaço para surgirem as comissões de trabalhadores.

A queda do regime deixava para trás um país europeu, colonialista, com uma estrutura social que combinava uma indústria pujante, uma burguesia em seus primeiros passos na internacionalização ${ }^{3}$ e um povo mantido com baixos salários, ignorância e atraso. Alguém lembrou que Portugal era, então, uma espécie de "Albânia atlântica", onde:

o divórcio é reprimido, onde há (muitos) livros, filmes e canções proibidas, onde todas as artes são censuradas, onde a comunicação social é amordaçada, onde muitas crianças andam descalças, onde a maior parte da população não dispõe de frigorífico, telefone, televisor ou casa de banho, onde não se pode dizer piadas sobre as autoridades ou criticar o poder, onde não há direito de manifestação ou greve, ou é preciso licença para ter isqueiro ou transístor a pilhas, onde a agricultura se faz com charruas medievais e tração animal, onde o movimento rodoviário se encontra pejado de carroças e carros de bois, onde o pronto-a-vestir é quase inexistente, onde a Coca-Cola é de contrabando, onde a polícia política exerce a tortura nas prisões, onde não há autoestradas nem... eleições. ${ }^{4}$

Este era também o país onde, na Metrópole, 30\% da população era analfabeta, não havia sufrágio universal, não havia um sistema de previdência universal e ir ao médico implicava sempre uma relação paternalista e comercial com as Santas Casas de Misericórdia, então controladas pela Igreja Católica. Cruz Oliveira, nomeado para a pasta da Saúde logo depois do 25 de Abril, orgulha-se de ter posto fim à dependência dos hospitais em relação às Misericórdias e de ter acabado com o negócio das senhas (os familiares tinham de pagar uma senha para ver um doente no hospital) e do sangue. "O sangue não se vende nem se compra, dá-se!” (entrevista aos autores, 24/02/2012). Final- 
mente, mesmo contando países como a Grécia e Espanha, Portugal ocupava o primeiro lugar com os mais baixos salários europeus (Barreto \& Preto, I996). O 25 de Abril foi, por isto, a data mais importante do século XX português porque pôs fim a um país e inaugurou outro.

"Quem precisa de patrões?",5 perguntava-se em janeiro de I975. A pergunta, tão vulgarizada então, teria sido herética nove meses antes. A ideia de que a fábrica ou a empresa poderia subsistir pela autogestão dos trabalhadores - e mais tarde, sobretudo a partir de abril de I975, evoluir noutras empresas para o controle operário - teria parecido, mesmo aos próprios trabalhadores, e talvez sobretudo a eles, uma impossibilidade antes da revolução.

A fábrica de Lanifícios Sousa Abreu foi ocupada em setembro de I974. A 30 de julho de I975, a Rádio e Televisão de Portugal (RTP), empresa estatal, através do programa "Temas e Problemas", foi ver como estava a fábrica autogerida. Sintomático também é que a RTP tivesse telejornais diários onde se descreviam as greves e as manifestações com entrevistas dos trabalhadores, programas em horário nobre, como o já referido "Temas e Problemas" ou o "Artes e Ofícios", que são dedicados às fábricas ocupadas ou à reforma agrária - o espaço do social tinha se refletido na programação da televisão, que se tornava cada vez mais um meio de comunicação de massas.

Na fábrica ocupada, uma operária, gorducha, de cabelos apanhados e bata, com forte sotaque do Norte, explica como trabalha, de onde vem o fio etc. "Trabalho aqui no caneleiro", diz com um sorriso aberto, mas jeito envergonhado por estar a ser filmada. O Sr. Ribeiro, outro operário, diz que a "ideia de ocupar a fábrica veio do sindicato: o presidente do sindicato, sabendo que isto ia fechar, disse para ocuparmos as instalações porque se não o patrão levava a matéria-prima e não pagava nem os salários em atraso nem as indemnizações".

À porta da fábrica, em julho de I975, um cartaz diz:

O trabalho não é uma mercadoria, é um direito. Queremos trabalhar para viver e não viver para trabalhar. Para o capitalista, o operário é uma máquina. Os capitalistas só se interessam pelos operários quando estes dão lucro [...]. Contra a exploração, direito ao trabalho!

Tudo começa em 8 de setembro de I974. Os trabalhadores dirigem-se à Sousa Abreu quando sabem da ameaça de dispensas. Tem lugar uma reunião geral de trabalhadores a I 5 de setembro, quando se elege três membros para a comissão de trabalhadores. Clara, uma operária, conta a sua história:

No princípio foi complicado... Estávamos poucos, na primeira noite estávamos mesmo muito pouquinhos. Foram-se juntando depois até pessoas de outras fábricas. Ocupamos a fábrica no dia 8 de setembro e começamos a trabalhar a partir do dia 16.

O filósofo Jean Paul Sartre, adepto das ideias maoístas, deixará, em março de I975, um testemunho impressionado com a fábrica Sousa Abreu e o funcionamento das comissões de trabalhadores: 
A [coisa] que mais me interessou foi certamente ter visto a fábrica autogerida Sousa Abreu. É uma fábrica de cerca de 30 operários da indústria têxtil. Os trabalhadores foram abandonados pelo patrão há uns seis meses e a maior parte dos equipamentos da fábrica, exceto as máquinas, foram levados pelo patrão para montar a fábrica noutro sítio.

Eles ficaram portanto sozinhos, e decidiram continuar o trabalho autogerindo-se. E conseguiram. Continuaram os trabalhos que faziam antes e continuaram a ser os mesmo que trabalhavam antes, salvo os secretários e, evidentemente, o patrão e alguns operários que partiram de livre vontade. Mesmo assim eles aumentaram a produção relativamente aos últimos tempos do patronato, porque a fábrica estava em crise e cheia de dívidas.

Constituíram um grupo de três a seis operários para as decisões gerais. Estas decisões são tomadas da seguinte forma: as decisões menos importantes são tomadas pelo grupo em questão; as decisões mais importantes são tomadas por toda a assembleia de fábrica, que é reunida e consultada sobre as decisões a tomar (extraído de Revista História, Lisboa, abril de 2004, s/p).

Sartre tinha vivido a experiência do Maio de I968, na França, onde a revolução tinha sido profunda, atingindo o coração da produção industrial francesa, com solidariedade entre setores distintos do movimento operário e setores estudantis, culminando na greve geral de um milhão de pessoas. Foi, porém, uma situação revolucionária extremamente curta, obedecendo a um padrão que Arcary (2004), por exemplo, crê existir e que corresponde ao seguinte: quando se dão processos revolucionários, estes se prolongam mais no tempo quanto mais atrasado é o país (menos urbano, mais pobre, menos escolarizado etc.). Inversamente, a tendência é para que quanto mais desenvolvido é um país, mais rapidamente uma situação revolucionária caminhe ou no sentido da contrarrevolução ou da vitória da tomada de poder pelos trabalhadores. Em suma, a questão é importante para se compreender também o deslumbramento de Sartre, porque Portugal não era uma Cuba rural nem uma França, onde a curta experiência não permitiu desenvolver processos autogestionários nas fábricas. Portugal era um país europeu, modernizado, com uma jovem população concentrada na indústria à volta dos grandes centros urbanos, e a revolução demorou I9 meses para ser derrotada.

Porém, a tarefa que se colocava a estes trabalhadores era enorme. Era ainda um estágio embrionário de gestão coletiva da riqueza social, estando-lhe colocadas todas as dificuldades que se colocavam a qualquer empresa no meio de uma crise econômica com o agravante de terem de aprender a gerir a produção. Uma das trabalhadoras da Sousa Abreu confessa que "se eu tivesse um patrão em condições preferia mais trabalhar para o patrão que por minha conta [...]. Se aparecesse um patrão [que tivesse consideração por nós] ... que hoje aliás poucos há assim...".

Vitorino Santos, projetista, dará mais tarde, já depois da revolução, uma entrevista na qual recorda que: 


\begin{abstract}
A autogestão também tem os seus problemas. Desapareceu a contradição entre capital e trabalho, mas surgiram problemas entre a comissão de trabalhadores e os trabalhadores. Houve quem se arvorasse ou tentasse arvorar-se em patrão [...]. Eu assisti na prática a situações desse tipo.

Aquele período foi no entanto muito rico. A liberdade, a solidariedade, a poesia estavam na rua. E não por decreto, não havia as agendas culturais de hoje, mas um projeto novo de sociedade. Não havia medo de andar na rua, havia uma sociedade menos egoísta. O único perigo era para a direita e para os do antigo regime. (Rodrigues, I994: 9I)
\end{abstract}

A história da ocupação da Sousa Abreu é muito semelhante a todas as ocupações deste período. Muitas delas são também motivadas pelo saneamento ${ }^{6}$ de elementos afetos ao antigo regime. Porém, neste caso, o determinante serão as dispensas e a galopante taxa de desemprego, e esta parece ser a razão principal das ocupações a partir de outubro de I974, uma vez que até aí muitos dos saneamentos de pessoas ligadas ao antigo regime tinham sido já feitos.

Perante a ameaça de dispensas por descapitalização da empresa os trabalhadores fazem piquetes e ocupam a fábrica para garantir que o patrão não leve as máquinas e assim não percam o trabalho. Ao dirigirem-se à fábrica veem-se confrontados com a necessidade de organização do local de trabalho e, seja por mimetismo com as outras fábricas e empresas, seja pela ausência de outras estruturas sedimentadas com uma hierarquia específica, como os sindicatos, decidem as coisas com os meios que têm: encontram-se na fábrica, começam a discutir. Se veem quase que espontaneamente no meio de plenário, decidem então eleger representantes e formam uma comissão de trabalhadores.

Não quer isto dizer que muitas vezes os próprios partidos políticos, com quadros dirigentes dos mais diversos quadrantes da extrema-esquerda, os partidos comunista e socialista, não estivessem próximos das fábricas e empresas e estimulassem este tipo de organização ou atuassem nela com o intuito de a dirigir ou codirigir - foi aliás muito comum que assim acontecesse.

Segundo uma contagem feita pela Confederação da Indústria Portuguesa (CIP), e sistematizada pelo historiador Miguel Pérez, "ter-se-iam registado 24 ocupações de empresas no último trimestre de 1974 , e 83, 55 e I4 nos I ${ }^{\circ}, 2^{\circ}$ e $3^{\circ}$ trimestres de 1975, respetivamente" (Pérez, 20I3: 6). São números que merecem ser analisados com alguma precaução e que estão muito aquém da totalidade das empresas (muitas são bastante pequenas, com 5, I 2, 20 trabalhadores, e não são registradas pela CIP), mas provavelmente há uma evolução do número de ocupações que vai paulatinamente de julho de 1974 a março e abril de 1975, verificando-se, depois desta data, por conseguinte a partir de abril e maio de I975, a manutenção da ocupação destas empresas, muitas, entretanto, sob intervenção do Estado, que passaram a ser autogeridas (frequentemente em ligação com o Ministério do Trabalho) e algumas destas evoluíram para uma situação de controle operário, que porém foi mais forte nas 
empresas nacionalizadas e em muitas que se mantiveram privadas, com especial destaque para o ramo da metal-mecânica:

A empresa torna-se um espaço de luta entre os trabalhadores e os capitalistas particulares, que sempre exerceram uma autoridade incontestada no interior das empresas. Agora, os trabalhadores consideram-se no direito de discutir as decisões do empresário e de pô-las em causa, e para isso recorrem a formas de luta radicais: a ocupação é a segunda forma de luta mais frequente (35 em I58, sempre segundo os números do GIS) e torna-se comum a aplicação unilateral da vontade dos trabalhadores na empresa em questões de horários e saneamentos. As Comissões de Trabalhadores (CTs) afirmam-se como a estrutura essencial de organização dos trabalhadores nas empresas. (Pérez, 2013: 6)

Nos jornais diários há colunas inteiras da seção Trabalho que são sobre a luta contra as demissões.

O comunicado dos trabalhadores de uma fábrica de produtos esmaltados de São Mamede de Infesta, no Norte do País, que tem já um conteúdo mais politizado, é revelador sobre o impacto das dispensas:

Tendo em conta que os patrões chegam ao cúmulo de nos impedirem de vender a única coisa que possuímos - a força de trabalho;

Tendo em conta que só a luta organizada da classe operária é capaz de fazer recuar a burguesia;

Nós, trabalhadores da Esmaltal, ocupamos as instalações com piquetes permanentes, sem paralisar o trabalho, como medida para defender os nossos legítimos direitos. Reivindicamos a intervenção governamental na empresa e a sua nacionalização. (Rodrigues, I994: 9I)

Uma das mais emblemáticas ocupações seguidas de autogestão é a da fábrica Sogantal, então propriedade da empresa A. Lammont, de capitais franceses, que "beneficiava-se dos magros salários e da ausência de pressão sindical antes do 25 de Abril" e onde havia "um ambiente de trabalho muito repressivo, com traços de paternalismo" (Pérez, 2008). A história da ocupação começa ainda em maio de I974. As operárias começam a reduzir os ritmos de trabalho como forma de pressão para conseguirem as reivindicações exigidas à empresa: um mês de férias pagas; I $3^{\circ}$ salário e, traços do igualitarismo salarial que se verifica em vários setores, um aumento geral de I $200 \$ 00$ escudos para todas, sem exceções. A administração reage no final de maio fechando a empresa. As operárias respondem de imediato exigindo, junto ao Ministério do Trabalho, a nacionalização e o pagamento dos salários pelo Estado.

A I3 de julho a Administração e o seu representante português abandonam as instalações. A fábrica fica nas mãos das operárias que continuam a trabalhar e vão começar a vender as reservas disponíveis para o pagamento de salários. Recebem a solidariedade de partidos e grupos de extrema-esquerda como o MES [Movimento Esquerda Socialista] e o MRPP [Movimento Reorganizativo do Partido do Proletariado], mas também da seção local do PS, assim como o apoio do Sindicato dos Têxteis e Vestuário do Sul. É organizada [pelas trabalhadoras da fábrica 
Sogantal] a venda militante de fatos de treino e escolas e fábricas. As primeiras vendas conseguem pagar parte das quantias devidas às trabalhadoras, que recebem o apoio solidário do músico José Afonso. (Pérez, 2008: 98-100).

A surpresa é total quando, na madrugada de 23 para 24 de agosto de I974, um grupo de duas dezenas de mercenários a soldo da administração francesa invade a fábrica e tenta retirar as máquinas. Populares e operárias reagem e forçam a entrada na empresa. Os homens e o patrão são alvo da fúria dos manifestantes. A Guarda Nacional Republicana (GNR) tem dificuldade em conter a população. "O comando abandona a empresa protegido por tropas no meio de apupos e insultos dos populares" (Pérez, 2008: 98-100). A partir daí a fábrica fica sob o controle das trabalhadoras, em sistema de autogestão:

A partir dessa altura (24 de agosto) começamos a dormir dentro da fábrica. [...] Fazíamos piquetes, enquanto umas trabalhadoras ficavam na fábrica outras iam vender a produção a diversas empresas e escritórios em vários pontos do país. Levávamos comunicados para divulgarmos a nossa luta e, nisso, éramos apoiadas pelos diversos sindicatos. Gerou-se uma solidariedade tal que, apesar de não necessitarem dos uniformes de treino, muitas pessoas compravam o produto só para nos ajudarem. E esse dinheiro todo junto dava para pagar os nossos salários. Conseguimos manter a fábrica durante mais de um ano e, entretanto, surgiu a hipótese da autogestão, ou seja, outras empresas darem-nos trabalho e nós utilizarmos a fábrica para produzir. (Pérez, 2008: 98-100)

\section{CARACTERÍSTICAS DAS FÁBRICAS E EMPRESAS EM AUTOGESTÃO}

As ocupações de empresas e fábricas por trabalhadores surgem de quatro fatores que parecem determinantes:

I. A resistência à descapitalização das empresas, com ameaças de demissões, no meio da maior crise econômica do pós-guerra e de um aumento galopante da taxa de desemprego.

2. A ausência de estruturas sólidas representativas dos trabalhadores já com uma hierarquia definida (sindicatos), portanto, a existência de um certo vazio de poder que abriu espaço ao poder das comissões de trabalhadores.

3. A limitação do poder repressivo por parte do Estado na defesa da propriedade privada (por crise na direção do Estado e, sobretudo, no Exército).

4. A existência de quadros políticos com programas revolucionários, digamos, um "encontro" da utopia de dirigentes formados no marxismo, na verdade em várias correntes que se 
reivindicavam marxistas, nos centros acadêmicos, escolas profissionais etc., com um forte impacto do Maio de I968, da revolução cubana e da revolução cultural chinesa, que se encontram com a "história", isto é, com uma situação revolucionária para a qual estavam teoricamente "preparados" ou, pelo menos, para sermos mais realistas, desejosos.

A seguir ao 25 de Abril, entre 1974 e I978, a realidade das empresas autogestionárias corresponde a 626 empresas em autogestão e 3 I 9 cooperativas (Comissão Coordenadora das Empresas em Autogestão et al., s/d). A autogestão é aprovada também no contexto do pacto social e fica inscrita na Constituição da República Portuguesa (CRP). Mas até I 975 estão registradas cerca de 300 empresas sob intervenção.

Decreto de Aprovação da Constituição n ${ }^{\circ}$ CRP I 976 de I0-04-I976

PARTE I - Direitos e deveres fundamentais

TÍTULO III - Direitos e deveres econômicos, sociais e culturais

CAPÍTULO II - Direitos e deveres econômicos

Artigo $6 \mathrm{I}^{\circ}$ - (Cooperativas e autogestão)

I. Todos têm o direito de constituir cooperativas, devendo o Estado, de acordo com o Plano, estimular e apoiar as iniciativas nesse sentido. 2. Serão apoiadas pelo Estado as experiências de autogestão.

Como refere a Comissão Coordenadora das Empresas em Autogestão (s/d), esta realidade surge de duas formas durante a revolução:

Por razões de salvaguarda dos postos de trabalho e da manutenção da produção, um conjunto de trabalhadores de empresas privadas, após o 25 de abril, começou a ser gerido pelos próprios trabalhadores.

Quer por acordo com as entidades patronais (que por vezes permanecem na empresa como trabalhadores) culminando na venda, arrendamento, ou cedência do património ao coletivo dos trabalhadores organizados juridicamente sob a forma de cooperativa;

Quer por processos de rutura conflituosos, em que as empresas se organizam juridicamente em cooperativas ou empresa de autogestão.

Será preciso esperar por 1976 para haver apenas parcialmente estabilidade governativa (até I985 existirão io governos!), para o Estado enquadrar, sem ser avulsamente e à medida da força social dos trabalhadores, as empre- 
sas em autogestão. A partir de I978 há um reenquadramento legal e muitas destas passam de novo para o setor privado.

Mas em I974 e I975 é a realidade da luta social que se impõe, sem que o Estado tenha meios para impor o seu poder sem ser questionado. Obriga-se assim o Estado ao papel de:

I. Protegê-las financeiramente de alguma forma, o que significa alocar recursos públicos para o fator trabalho de facto porque evita a destruição de riqueza, como medida contracíclica, isto é, como medida para recuperar a taxa de lucro.

2. Enviar forças de repressão toleradas pelos trabalhadores, caso comum do COPCON, quando em situações extremas há confronto físico entre trabalhadores e patrões, sobretudo quando alguns destes patrões procuram retirar as máquinas ou documentação importante.

3. Tentar enquadrar - e essa política é feita, quer pelo Partido Socialista (PS), quer pelo Partido Comunista Português (PCP) (Varela, 20 I I) - o processo numa gestão econômica que evite a luta política, numa articulação estreita entre os trabalhadores, os sindicatos em formação e o Ministério do Trabalho, dirigido sobretudo pelo PCP.

A figura a seguir ilustra o processo, na sua gênese, logo depois do 25 de Abril:

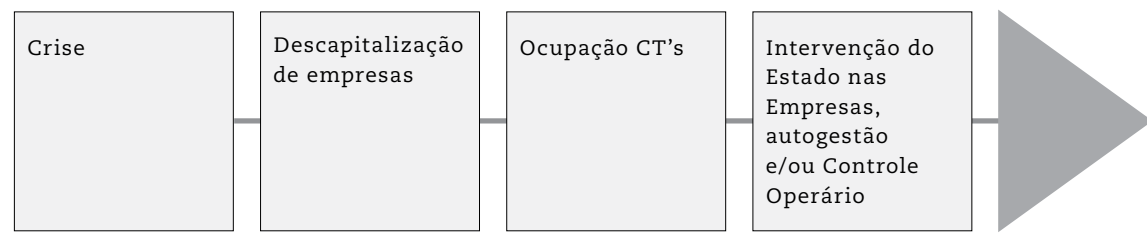

Figura I - Evolução do Processo Autogestionário

Fonte: Própria.

Na evolução autogestionária portuguesa os fatos precederam o direito e entre I974 e I975:

Atingiu-se, em muitas empresas, uma situação de rutura econômica e social com afastamento, voluntário ou involuntário, da entidade patronal e início de uma gestão conduzida pelos trabalhadores, através de uma comissão designada em plenário.

A necessidade prática de reconhecimento dos atos desta comissão pelos terceiros que com ela entravam em relações (fornecedores, clientes, entidades oficiais) determinou uma intervenção dos poderes públicos através de uma declaração oficial credenciando a comissão para representar a empresa. Foram as credenciais passadas sobretudo pelo Ministério do Trabalho (Comissão Coordenadora das Empresas em Autogestão et al., s/d: I5I). 
Este diálogo na empresa Mayombe atesta o clima que então se vivia. Veem-se à entrada vários trabalhadores num piquete. O irmão do patrão aborda-os:

Trabalhador a gritar: "O senhor anda há 8 dias aqui a vir a provocar os trabalhadores e isto tem que acabar. Os trabalhadores decidiram! O senhor respeite a vontade dos trabalhadores! Os trabalhadores querem continuar com a firma a funcionar e o senhor não quer deixar, vem aqui provocar os trabalhadores. Os trabalhadores querem que o senhor vá para a rua, que continue o processo de saneamento e depois damos-lhe conhecimento do que for decidido [...]

[...] E olhe, uma pergunta, o Estado também reconheceu o seu irmão para levar milhares, desviar milhares, para o estrangeiro?"

Irmão do patrão: "Isso é uma afirmação gratuita que está a fazer".

(É interrompido.)

Trabalhador (aos gritos): "Não são afirmações gratuitas! A Polícia Judiciária prendeu-o e não o prendeu sem motivos, 'tá a ver? Mais: por que é que o seu irmão boicotou sempre a comissão de trabalhadores? Boicotou sempre os delegados sindicais?"

Irmão do patrão (com voz pausada): "Só berras mais do que eu, mais nada".

Trabalhador: "Mas berro com voz de trabalhador, você berra com voz de fascista!".

(Furtado et al, I994: minutos I.03.43-I.05.40)

\section{A CRISE ECONÓMICA DE 1970-1973 E A AUTOGESTÃo}

Os processos de autogestão têm como pano de fundo a crise econômica e não o "caos" que teria sido provocado pelo controle da produção. As quedas da produtividade em I974-I975 prendem-se muito mais com efetiva ausência de encomendas, por exemplo, do que com perdas na qualidade da gestão, segundo o relatório feito pelo Massachussetts Institute of Technology, a pedido do Banco de Portugal, realizado em 1976 (Dornbusch et al., I976).

A tentativa de recuperar as taxas médias de lucro, em queda por força da crise, vai ser a causa da descapitalização de empresas, fuga de capitais, pressão para demissões, como vimos.

É a maior crise desde a II Guerra Mundial, que começa em I970-I97 I e vai até I973, só havendo sinais de recuperação, a nível mundial - sinais que são desiguais, consoante os países -, a partir do final de I975. Em março de I974, portanto ainda com o regime de pé, o Sindicato dos Caixeiros de Lisboa publica um boletim contra a carestia de vida, a defender a luta dos trabalhadores cujos salários tinham sido literalmente engolidos pela inflação: em 6 meses, entre outubro de 1973 e março de I974, o bacalhau subiu I I3\%, as batatas, $80 \%$, a gasolina, $66 \%$. O que tinha acontecido?

Para além da guerra - fator histórico essencial já indicado por vários historiadores para explicar as causas das revoluções (veja-se a Comuna de Paris de I97I, nascida da derrota francesa na guerra franco-prussiana, e a revolução russa de I905, da guerra russo-japonesa, ou a de I9I7, da I Guerra Mundial) - a revolução portuguesa é engendrada na recessão mundial que 
começa em I973 e se tornou a mais grave crise econômica do pós-guerra: "não há dúvida" sobre o impacto da "crise atual do capitalismo mundial no desmoronamento econômico em Portugal” (Schmitter, I999: 226).

O marxismo trabalhou sempre com o conceito de crise econômica como parte essencial da desestabilização nacional. Era, portanto, um momento de dificuldades acrescidas para manter a estabilização do Estado porque:

I. Por um lado, implicava menor divisão do bolo da riqueza social e, portanto, um aumento de conflitos entre as diversas frações da burguesia pela apropriação da mais-valia, um momento em que quem governa o Estado se encontra mais frágil, com menos capacidade de gestão dos equilíbrios sociais.

2. E, por outro, porque as medidas contracíclicas, medidas que visam recuperar a taxa de rotação e acumulação do capital (como fechar empresas, desempregar pessoas, intensificar a jornada de trabalho, cortar salários diretos ou indiretos) geram, tendencialmente, situações de conflito mais acirradas.

É um fato que esta variável nas revoluções - a variável do impacto das crises econômicas - deve ser matizada sobretudo quando ainda hoje a historiografia vive aquilo que se pode designar até como um certo "trauma" com as correntes teóricas pró-soviéticas que exacerbaram um determinismo econômico que veio a revelar-se falso, baseado na hipótese de que o capitalismo teria uma espécie de colapso final (Arcary, 2006). A reação a este determinismo foi, por parte de um importante setor da historiografia, a construção de uma história político-institucional que quase desprezou os fatores econômicos, estando ainda hoje a crise mundial de 1973 ausente da maior parte dos trabalhos sobre a revolução portuguesa, olvidando que são as medidas recessivas face à crise que fecham as empresas, e que os trabalhadores em reação a isso ocupam as fábricas, e não o contrário. As fábricas ocupadas não entraram em crise por baixa da produtividade; foi a superprodução que determinou o seu encerramento ou diminuição da produção.

Há um efeito disruptivo nas lutas sociais - sobretudo porque ocupam a propriedade, questionando o próprio modo de acumulação -, mas é um efeito, antes de tudo mais, político e econômico que é precedido pelo cataclismo da crise de I970 que leva a inflação e a destruição de emprego ao mundo todo, como um fantasma.

Debrucemos por um momento o olhar sobre o processo histórico desde I 825 - quando a primeira crise cíclica do capitalismo surpreende os economistas, na sua maioria incapazes de a explicar, acreditando que a acumulação de capital não tinha limites. Observa-se, historicamente, que a crise econômica, cíclica, é parte indispensável, mas não suficiente, da abertura de um processo revolucionário. 
É exato que, como assinala o historiador Valério Arcary, as causas das revoluções caminham de forma desigual:

A disposição revolucionária das massas e a crise nacional [são] fatores que caminham em paralelo, mas de forma variável e desigual [...]. As crises econômico-sociais podem se agravar antes que as massas entrem em cena, ou, inversamente, os sujeitos sociais explorados podem se lançar à luta primeiro em países onde a crise pareceria menos severa que em outros (Arcary, 2004: 38).

Leon Trotsky, na sua História da revolução russa (I988), 7 destacou três elementos que caracterizam uma situação como revolucionária: a entrada em cena de milhões de trabalhadores mobilizados, atração dos setores intermédiários da sociedade pelas organizações e métodos de luta das classes trabalhadoras e uma crise nacional (mais tarde, em I93I, Trotsky acrescentará a esta definição a existência de um partido revolucionário) (Trotsky, I93I). Em suma, uma situação revolucionária seria um processo político caracterizado pela entrada em cena de vastos setores da população (trabalhadores e classes médias) que altera a relação de forças entre classes sociais, num quadro de crise (decadência) nacional.

Mas no caso português caminharam em conjunto: guerra e crise econômica, duas dimensões da "crise nacional". A crise econômica atingiu a classe dominante nacional, provocando divisões no seu seio e praticamente inviabilizando o esforço de guerra que já devorava $40 \%$ das despesas do Estado (e $8 \%$ do PNB).

Em Portugal, a taxa de variação do Produto Interno Bruto passa de i I,2\%, em I973, para I,I\% em I 974 e -4,3\% em I 975 . No caso português há uma tempestade perfeita - expressão que se usa para designar quando todos os fatores confluem num mesmo ponto: I) crise econômica; 2) guerra; 3) desorganização e desenquadramento do movimento operário em estruturas fortes capazes de conter ou ser focos orgânicos de negociação com o Estado; 4) um proletariado jovem e concentrado.

Foi uma surpresa para o mundo todo ver que aquele país de "velhinhas tristes de bigode, vestidas de preto, desdentadas" ${ }^{8}$ era agora um país onde esta gente pobre ocupava a antiga casa do senhor, de um "morgadinho" (por referência à lei novecentista que dava a propriedade ao filho mais velho, normalmente acusado de parasitismo) num bairro do Porto, Lisboa ou Setúbal, para fazer uma creche, e vinham os carpinteiros do bairro e faziam as camas e vinha o eletricista montar a eletricidade e, finalmente, vinha o MFA e dizia, quase sempre: "Muito bem."

A inflação de dois dígitos tem a sua origem, em primeiro lugar, na desvalorização maciça do dólar em I970-I973, um impacto enorme em todo o mundo e sobretudo em países semiperiféricos como Portugal, a braços com uma guerra que se tornou, a partir daí, e também (mas não só) por razões econômicas, insustentável. A este fato juntou-se o desgaste da guerra de guerrilha e surge, neste âmbito, o Movimento de Capitães, mais tarde Movimento das Forças Armadas, que deu o golpe de Estado de 25 de Abril de I974. A importância da guerra e do Movimento de Capitães não pode ofuscar a dimensão da crise econômica. 
Em I97I, os EUA deram um golpe de graça na "ordem econômica" elaborada em I945. A maior parte das moedas tornaram-se flutuantes e foi apenas com o Smithsonian Agreement, realizado em Washington a i 8 de dezembro de I97 I, que foi oficializada uma desvalorização de $7,89 \%$ do dólar, fixando o preço da onça do ouro em 38 dólares. Essa decisão trouxe um reajuste geral das moedas, enquanto as margens de flutuações, fixadas em I\% quando dos acordos de Bretton Woods, passavam a $2,25 \%$. O dólar ficava inconvertível; a parte do estoque de ouro dos EUA caiu a $28 \%$ do estoque mundial e o déficit do seu balanço de pagamentos atingiu 23,5 bilhões de dólares. A crise econômica é a união forçada de dois elementos que se tornaram independentes no processo de produção e valorização. Produção e circulação, que são dois elementos constitutivos do processo global de reprodução ampliada do capital, se separam quando há superprodução e as mercadorias não podem ser "realizadas", isto é, vendidas: há um desatrelamento entre compra e venda, entre a produção e o consumo. A crise é exatamente o reagrupamento forçado desses dois momentos da reprodução econômica da sociedade, mediante a queda vertiginosa de preços, falência de produtores, desemprego de trabalhadores, queda do poder aquisitivo da população, destruição física de mercadorias etc. Como qualquer crise de grande amplitude, a que sacudiu o mundo na primeira metade dos anos 1970 foi gerada por múltiplos fatores: escassez de petróleo, péssima circulação monetária, guerra comercial, luta de classes acirrada etc. (Coggiola, 2006: 69)

Ela, “a crise aí está, com todo o seu cortejo de consequências, incontrolável, indomável. Afrouxamento do crescimento, subida do desemprego, aumento da inflação, baixa do poder de compra dos trabalhadores", lembra Michel Beaud (I992: 260). "Em I 974 a produção nos Estados Unidos tinha caído Io,4\% e o desemprego situava-se em 9\%" (Coggiola, 2006: 26I). A taxa de crescimento anual do Produto Interno Bruto dos EUA passa de 4,7\%, em I970-I973, para 2,4\%, em I973-I978; na Grã-Bretanha, de 4,3\% para o,9\%; no Japão, de 8,I\% para 3,7\%, e o número de desempregados triplica na Grã-Bretanha e na República Federal Alemã entre i973 e I977, para citar alguns exemplos (Beaud, I992: 260). A maior crise econômica do pós-guerra tinha começado nos Estado Unidos da América.

A opinião pública no mundo ocidental parece não ter se conscientizado dessa crise senão em outono de 1973, depois que quadruplicou o preço do petróleo. A memória é curta. Antes de tomar a aparência de uma crise das matérias-primas, lembremo-nos que a partir do I5 de agosto de I97I, esta crise já tinha começado a se manifestar sob sua forma monetária. (Coggiola, 2006: 63)

Esta crise não foi simplesmente uma crise conjuntural cíclica como as anteriores (I948-I949; I952-I953, I957-I958, I960-I96I, I966-I967, I970-I97I), mas uma crise que atingiu limites profundos do capitalismo.

A crise econômica internacional atinge "severamente Portugal", escreveu Silva Lopes (I999), então ministro da Economia, num trabalho que mais tarde fez sobre a evolução econômica do País. Segundo Eugénio Rosa (I975), entre janeiro e dezembro de 1974 o desemprego sobe para o dobro, sendo as áreas de Lisboa, Porto e Setúbal as mais afetadas em termos absolutos, e o Alentejo e Algarve, em termos relativos. 
Isto num país que quase tinha pleno emprego, fruto de uma economia de guerra (entre I96I-I974) que mobilizava trabalhadores para deles fazer soldados, impulso de transformação num país definitivamente moderno e industrial (embora desigual e combinado), cuja produção para a guerra tinha um efeito dinamizador sobre alguns setores da economia privada (mas ao mesmo tempo com erosão das contas públicas), com a emigração massiva dos anos I960 (e respetivas remessas de emigrantes). Silva Lopes assinala o extraordinário impacto do desemprego e da descapitalização de empresas nos processos autogestionários e, mais tarde, na decisão de intervenção do Estado nas empresas:

Com a explosão dos conflitos sociais nos primeiros meses a seguir ao 25 de Abril, os trabalhadores de muitas empresas expulsaram os patrões ou os seus representantes, invocando argumentos de sabotagem econômica, colaboração com o regime de ditadura, repressão laboral etc. Ao mesmo tempo, a deterioração das condições econômicas das empresas ia empurrando muitas delas para situações insustentáveis de falta de liquidez ou solvência e levou muitos donos a abandoná-las. Para protegerem os seus empregos, ou para arrancarem todo o poder aos proprietários do capital, os trabalhadores das empresas assim atingidas apoderaram-se da respetiva gestão e reclamaram apoios do Estado para as manterem em atividade. O Governo foi, por isso, levado a publicar alguns diplomas que davam cobertura legal às situações assim criadas. [...] Esses diplomas estabeleciam e regulavam os mecanismos de intervenção do Estado em sociedades privadas, embora a título temporário e sem deixarem de manter os meios de produção na titularidade dos respetivos proprietários. (Lopes, I999: 308)

\begin{tabular}{|c|c|c|c|}
\hline & $\begin{array}{l}\text { outubro de } 1973 \\
\text { (em escudos) }\end{array}$ & $\begin{array}{l}\text { março de I974 } \\
\text { (em escudos) }\end{array}$ & $\%$ de aumento \\
\hline Arroz & $8 \$ 90$ & IO\$70 & $20 \%$ \\
\hline Azeite & $35 \$ 00$ & $53 \$ 00$ & $50 \%$ \\
\hline Bacalhau & $44 \$ 00$ & $94 \$ 00$ & II $3 \%$ \\
\hline Batatas & $2 \$ 50$ & $4 \$ 50$ & $80 \%$ \\
\hline Bife & $60 \$ 00$ & $90 \$ 00$ & $50 \%$ \\
\hline Chouriço & $45 \$ 00$ & $75 \$ 00$ & $66 \%$ \\
\hline Frango & $26 \$ 00$ & $38 \$ 00$ & $46 \%$ \\
\hline Fiambre & $54 \$ 00$ & $85 \$ 00$ & $57 \%$ \\
\hline Gás & $72 \$ 00$ & $98 \$ 00$ & $36 \%$ \\
\hline Gasolina & $5 \$ 70$ & $9 \$ 50$ & $66 \%$ \\
\hline Óleo & I9\$0o & $28 \$ 00$ & $47 \%$ \\
\hline
\end{tabular}

Tabela I

Fonte: Sindicato Nacional dos Caixeiros de Lisboa, Circular n I5/74. 
As crises no sistema capitalista manifestam-se por uma deflação ou queda nos preços dos ativos financeiros, como desvalorização das ações em bolsa, dos títulos de crédito, hipotecas etc. Na prática, isto significa uma desvalorização do patrimônio e uma queda na taxa de lucro. Nessa altura observa-se, por um lado, uma queda na atividade econômica, nomeadamente na industrial. Por outro lado, os governos e bancos centrais lançam mão de medidas para contrariar esse movimento, como baixa da taxa de juros de maneira a tornar o acesso ao dinheiro mais barato e incentivar um aumento no investimento. Por outro lado, geram-se uma série de medidas, já referidas, que a curto prazo devem intensificar a extração de mais-valia - redução do horário de trabalho, recessão (destruição de emprego, encerramento de fábricas, o que em alguns casos leva à destruição, reestruturação ou deslocalização de determinados setores, levando também à concentração de empresas); intensificação das tarefas dadas ao trabalhador, cortes salariais diretos ou indiretos (por via de aumento dos impostos, inflação que "come" salários. Grosso modo, são estas as chamadas medidas contracíclicas (Rosdolsky, 200I).

Como referimos, as medidas contracíclicas visando recuperar a taxa de acumulação do capital podem gerar conflitos sociais mais acirrados. Do lado da produção, é em primeiro lugar o impulso do movimento operário para a elevação dos salários (Beaud, I992: 26I).

A reação do Governo - que estava então no III Governo Provisório (Governo de frente popular que existiu entre setembro de I974 e março de 1975) - vai ser a promulgação de um decreto de intervenção do Estado nas empresas. O Decreto-Lei $\mathrm{n}^{\circ} 660 / 74$, que estipulava que o Estado intervinha nas empresas em caso de abandono, descapitalização, não pagamento propositado a fornecedores, fraudes fiscais. Porém, a maioria das empresas sob intervenção só o serão a partir de abril e maio de I975, com o desenvolvimento do controle operário, que evoluiu efetivamente e partir de fevereiro de I975 (Varela, 20I4).

Nas empresas nacionalizadas, nas principais empresas de metal-mecânica e mesmo noutros setores entra-se numa situação de controle operário para além da autogestão, mais estabelecida nas pequenas empresas e nas empresas em reais dificuldades financeiras e/ou produtivas. O controle operário é um processo de dualidade de poderes que consiste na organização política dos trabalhadores no nível da produção - formalizada ou não - com vista a tomar o poder político. Este fenômeno específico distingue-se da autogestão (forma em que os trabalhadores passam a ser patrões de si próprios) e da cogestão (os trabalhadores estão, normalmente através dos sindicatos, a gerir as empresas e/ou fábricas em parceria com os patrões e/ou com o Estado). Até ao final da revolução, que retrocede a partir do golpe de Estado contrarrevolucionário de 25 de novembro de I975, o controle operário vai ser determinante e expressa a radicalização da revolução. Manter-se-ão as empresas autogeri- 
das mesmo para além de I975, embora com a estabilização da produção capitalista tenham declinado até desaparecerem por completo.

Recebido em 08/08/2014 | Aprovado em I3/02/2015.

Raquel Varela é doutora em História Política e Institucional (ISCTE - Instituto Universitário de Lisboa). É investigadora do Instituto de História Contemporânea da Universidade Nova de Lisboa e do Instituto Internacional de História Social. Publicou, entre outros livros: História do povo na Revolução Portuguesa (20I4) e Revolução ou transição? História e memória da Revolução dos Cravos (2012).

António Simões do Paço é investigador do Instituto de História Contemporânea (FCSH, Universidade Nova de Lisboa). É editor executivo da revista científica Workers of the World. Coordenou e foi co-autor de Os anos de Salazar, 30 volumes.

Joana Alcântara é mestranda em Antropologia pela Faculdade de Ciências Sociais da Universidade Nova de Lisboa.

Pedro Almeida Ferreira é doutorando no Programa Interuniversitário em História: mudança e continuidade num mundo global (PIUDHist). 
496

\section{NOTAS}

I Comentário de um jovem trabalhador da fábrica de lanifícios ocupada Sousa Abreu, transcrito do Programa "Temas e Problemas", 30 de julho de 1975, Arquivo Histórico da RTP.

2 No levantamento que realizamos com Alejandro Lora e Joana Alcântara, registramos centenas de reuniões na primeira semana que se segue ao golpe, mas é um levantamento centrado nos principais jornais, deixando de fora várias regiões do País e provavelmente centenas ou mesmo milhares de pequenas empresas.

3 A Lisnave, por exemplo, do poderoso grupo Companhia União Fabril (CUF) é fundada na década de I96o com capitais portugueses, suecos e holandeses.

4 Editorial, Revista Visão, Especial 25 de Abril, I5 de abril de 2004, p. I.

5 Título de uma notícia sobre a situação na Quinta de Comenda Torralta, onde uma exploração agrícola sofreu intervenção (Esquerda Socialista, I975: 5).

6 Termo singular utilizado no processo revolucionário português como sinônimo de expurgar. Refere-se à expulsão de indivíduos das direções das empresas, de organismos do Estado etc., ligados ao Estado Novo.

7 Ainda hoje, de forma inexplicável, fora dos programas de estudos universitários de História em Portugal - trata-se de uma das mais importantes obras de história da revolução russa, cuja leitura é obrigatória, por exemplo, no MIT.

8 E que maravilhoso teria sido se isto não passasse de mera caricatura! Mas não era: a pobreza e a subnutrição vinham associadas ao bócio endêmico, atrasos mentais, baixa estatura, surdez e mudez mais frequentes, má dentição em importantes setores mais pobres da população. 


\section{REFERÊNCIAS BIBLIOGRÁFICAS}

Arcary, Valério. (2006). O encontro da revolução com a história. São Paulo: Xamã.

Arcary, Valério. (2004). As esquinas perigosas da história. Situações revolucionárias em perspetiva marxista. São Paulo: Xamã.

Arcary, Valério. (2004). Quando o futuro era agora. Trinta anos da Revolução Portuguesa. Outubro, I I, p. 7 I-92.

Barreto, António. (2005). Mudança social em Portugal: I 960-2000. In: Costa Pinto, António (org.). Portugal contemporâneo. Lisboa: D. Quixote.

Barreto, António \& Preto, Clara Valadas. (I996). Portugal I 960/I 995: Indicadores sociais. Mirandela: Público.

Beaud, Michel. (I992). História do capitalismo. Lisboa: Teorema.

Coggiola, Osvaldo \& Martins, José. (2006). Dinâmicas da globalização (mercado mundial e ciclos económicos - 1970-2005). São Paulo: Instituto Rosa Luxemburgo.

Comissão Coordenadora das Empresas em Autogestão et al. (s/d). A realidade da autogestão em Portugal. Lisboa: Perspectivas e Realidades.

Dornbusch, Rudiger et al. (1976). Analysis and projections of macroeconomic conditions in Portugal. Report from OCDE sponsored mission to Portugal, December, I975. Lisboa: MIT - Department of Economics.

Esquerda Socialista. (I975). Quem precisa de patrões?". Esquerda Socialista, I I, I4 de janeiro.

Furtado, Joaquim et al. (I994). Portugal 74-75 - o retrato do 25 de Abril. Disponível em: < https://www.youtube.com/ watch?v=AEIPkal6848>. Acesso 23 set. 2013.

Lopes, José da Silva. (I999). A economia portuguesa desde I960. Lisboa: Gradiva.

Pérez, Miguel. (20I3). A mobilização operária anticapitalista na Revolução de I974-75. Comunicação apresentada ao I Congresso de História do Movimento Operário e dos Movimentos Sociais. Faculdade de Ciências Sociais e Humanas, Universidade Nova de Lisboa, I5-I7 de março. 
Pérez, Miguel. (2008). Contra a exploração capitalista. Comissões de trabalhadores e luta operária na Revolução Portuguesa (I974-75). Dissertação de Mestrado em História dos Séculos XIX e XX. Faculdade de Ciências Sociais e Humanas, Universidade Nova de Lisboa.

Rádio e Televisão de Portugal - RTP. (I975). Programa Temas e Problemas. s/l: Departamento de Programas Político-Sociais da RTP, 30 de julho.

Rodrigues, Francisco. (I994). O futuro era agora. Lisboa: Dinossauro.

Rosa, Eugénio. (1975). A economia portuguesa em números. Lisboa: Moraes Editora.

Rosdolsky, Roman. (200I). Génese e estrutura de O Capital em Marx. Rio de Janeiro: Contraponto.

Schmitter, Philip. (I999). Portugal: Do autoritarismo à democracia. Lisboa: ICS.

Trotsky, Leon. (I988). História da Revolução Russa. Lisboa: Versus.

Trotsky, Leon. (I93I). What is a revolutionary situation. The Militant, IV/36, p. 4.

Varela, Raquel. (20I4). História do povo na Revolução Portuguesa, I974-1975. Lisboa: Bertrand.

Varela, Raquel. (20I I). A história do PCP na Revolução dos Cravos. Lisboa: Bertrand. 


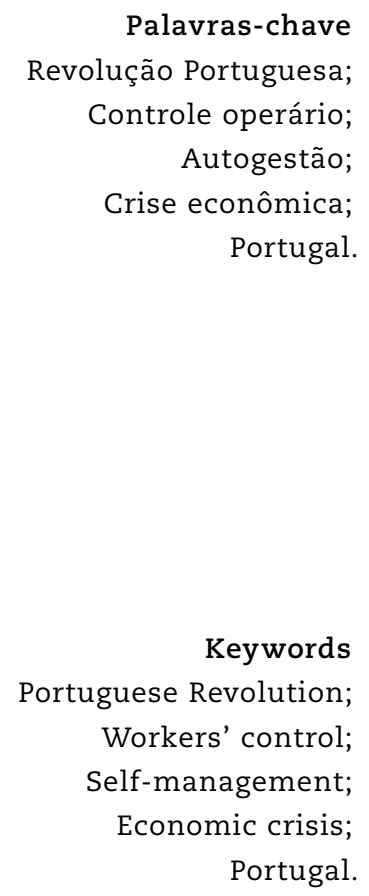

\section{AUTOGESTÃO E CRISE ECONÔMICA NA REVOLUÇÃo PORTUGUESA (1974-1975)}

O golpe militar de 25 de abril de 1974 é o ato inaugural da última revolução social europeia do século XX. Uma revolução política democrática logo metamorfoseou-se numa revolução social com a expressiva participação da classe trabalhadora e dos setores populares e estudantis. O longo regime ditatorial colapsou com a derrocada do controle político pelas Forças Armadas. Neste artigo analisamos a história dos processos autogestionários durante o período revolucionário iluminando sua relação direta com a crise econômica mundial de I973-I975.

\section{SELF-MANAGEMENT AND ECONOMIC CRISIS IN PORTUGUESE REVOLUTION (1974-1975)}

\section{Abstract}

The military coup of April 25, I974 was the inaugural act of the last European social revolution of the twentieth century. A democratic political revolution soon turned into a social revolution with the expressive presence of the working class and popular and student sectors. The dictatorial regime collapsed with the end of the political control exerted by the Armed Forces. This article analyses the self-management processes that occurred during the revolutionary period in Portugal, relating them to the global economic crisis of I973-1975. 